\title{
The Association of Gastritis and Peptic Ulcer With Polymorphisms in the In- flammatory-related Genes IL-4 and IL-10 in Iranian Population
}

\author{
Meysam Rezaeishahmirzadi', Neda Motamedi Rad', Mehdi Kalantar ${ }^{2}$, Hossein Ayatollahi ${ }^{3}$, Sepideh Shakeri, \\ Maryam Sheikhi ${ }^{3}$ Mohammad Shekari ${ }^{*}$ \\ 1. Dept. of Medical Genetics, Hormozgan University of Medical Science, Bandarabas, Iran \\ 2. Research and Clinical Center for Infertility, Shahid Sadoughi University of Medical Sciences, Yazd, Iran \\ 3. Cancer Molecular Pathology Research Center, Ghaem Hospital, Mashhad University of Medical \\ Sciences, Mashhad, Iran
}

\begin{tabular}{c}
\hline KEYWORDS \\
\hline Interleukin; \\
Gastritis; \\
Polymorphism; \\
Peptic Ulcer \\
\hline
\end{tabular}

Article Info

Received 17 Sep 2016;

Accepted 05 April 2017;

Published Online 17 July 2018;

\section{ABSTRACT}

Background \& Objective: The current study aimed at assessing the relationship between gastritis and peptic ulcer susceptibility and inflammation-related gene polymorphisms in Iranian patients. Gastritis and peptic ulcer are common medical complications with serious outcomes on the quality of life. Inflammatory responses of gastric mucosa are associated with helicobacter pylori, but most infected patients remain asymptomatic. There is strong evidence that inflammatory response is a major part of its etiology.

Methods: The current case-control study aimed atexamining genetic polymorphisms in inflammatory cytokines interleukin (IL)-4, and IL-10 using polymerase chain reaction-variable number tandem reaped (PCR-VNTR) and PCR-restriction fragment length polymorphism(RFLP) methods, respectively in 603 genotyped patients admitted to Mohammadi Hospital in Bandar Abbas, Iran(198 patients with gastritis, 84 with peptic ulcer, and 321 patients as controls).

Results: No significant associations were detected in genotype and allele frequencies of IL-10 and IL-4 between the case (with gastritis and peptic ulcer) and control groups.

Conclusion: In conclusion, the results of the analyses suggested that these polymorphisms may not predispose the carriers to gastritis and peptic ulcer development.

\section{Introduction}

A large body of epidemiological evidence display a relationship between Helicobacter pylori infection, gastritis, and peptic ulcer (1). H. pylori infection can activate inflammatory cytokines, inflammatory cells, and arouse free radical species following malignant transformation. According to genetic variations, people responses to inflammation may influence the degree of inflammation and then the risk for cancer (2).

H. pylori has a global distribution with a prevalence of $25 \%$ in the developed countries and $90 \%$ in the developing countries (3). However, clinical evidence is only observed in a small population, which suggests involvement of many other factors such as host factors in its pathogenesis (4). Chronic gastric inflamt mation, activated neutrophils, and mononuclear cells produce a variety of cytokines vital to regulating inflammation (5). Moreover, inflammation is mediated by pro- and anti-inflammatory cytokines suggesting that genetic polymorphisms of cytokine genes directly affect diversity of people and cytokine responses, which may affect clinical outcomes in different people. The pleiotropic cytokine interleukin (IL)-10 has a dual capability to suppress cancer immunity (6). $I L$ 10 restricts production of pro-inflammatory cytokines by limiting Th1 and stimulating Th2 and B-lympho- 
cytes, and thus downregulates inflammatory responses $(7,8)$. Human $I L-10$ gene is located on the long arm of chromosome 1q31-32, comprising five exons and three introns, with three polymorphisms identified in its promoter region-592 $(\mathrm{C}>\mathrm{A}),-1082(\mathrm{G}>\mathrm{A})$ and $-819(\mathrm{C}>\mathrm{T})$ affect expression of $I L-10$, and are associated with increased risk of gastric cancer $(7,9)$. The anti-inflammatory cytokine $I L-4$ has a key role in activation and differentiation of mast cells, erythrocytes, B-cells, and development of Th2, which is a subgroup of lymphocytes. Similar to $I L-4, I L-2$ and $I L-10$; Th2 causes production of antibody in human (10). A polymorphism is situated in the intron 3 of the gene, which contains a 70-bp variable number tandem repeat (VNTR). Frequency of VNTR repeats varies from two to four times, triple repeat is more common, and is observed in $76 \%$ of people.

The double repeat is less common, and is observed in $23 \%$ of people. Also, quadruple repeat is very rare, and is reported only in specific populations and races. The triple repeat causes greater production of $I L-4$ $(11,12)$. Therefore, the current study aimed at measuring the association of IL-10 and IL-4 polymorphisms with increased risk of gastritis and peptic ulcer.

\section{Materials and Methods}

People presenting with stomachache and indigestion diagnosed with gastritis or peptic ulcer accompany H. pylori infection according to endoscopy and histopathology findings were enrolled as the patient group. Patients that used non-steroidal anti-inflammatory drugs (NSAIDs) and the ones under the treatment for H. pylori were excluded. People with the history of exposure to $H$. pylori or active or chronic $H$. pylori infection (according to their serology tests) with no gastric problems or history of gastrointestinal diseases were selected as the control group. The current study protocol was approved by the Ethics Committee of the institute, and written informed consent was obtained from both control and case groups.

\section{Endoscopy and Gastric Histology}

Endoscopy was conducted using a video processor and video gastroscopy for every patient (Fujinon, Wayne, NJ, USA). The researcher took two biopsies from the corpus, antrum, or ulcer edge of every patient; one specimen was immediately fixed in the formalin for histological testing, and the other was placed in distilled water for diagnosis stage. The biopsies of detection were kept at $-20^{\circ} \mathrm{C}$ until processing stage. The pathological sections were stained with Hematoxylin \& Eosin, and assessed by a pathologist using Sydney System criteria (13). Therefore, endoscopic observation and histopathological confirmations were used to characterize patients' pathology.

\section{Serology}

Blood samples $(5 \mathrm{~mL})$ were taken from all control subjects of the study. The serum was tested for IgG by the enzyme-linked immunosorbent assay (ELISA) kit, according to the manufacturer's instruction. The specificity and sensitivity of the method is $97 \%$. A subject is considered positive, if antibody is detected in her/his serum.

\section{Analysis of $I L-4$ and $I L-10$ Genes}

In the current study, genomic DNA was extracted from the entire blood using a QIAamp DNA Mini Kit (QIAGEN, USA). A polymerase chain reaction (PCR)-VNTR assay was amplified to detect $I L-4$ (intron 3) 70-bp VNTR polymorphism in the primer sequence as described by $\mathrm{Wu}$ et al. (14). The PCR ree action mixture contained $100 \mathrm{ng}$ of genomic DNA, 20 pmol of each primer, and $0.3 \mathrm{mM}$ of each dNTP, 10X KCL, $1.5 \mathrm{mM} \mathrm{MgCl} 2$, and 1.5 units of Taq polymerase. First, the sequence of cycling was conducted at $95^{\circ} \mathrm{C}$ for four minutes, and then, 35 cycles were run at $95^{\circ} \mathrm{C}$ for 30 seconds followed by $59^{\circ} \mathrm{C}$ for 40 seconds, which specified at $73^{\circ} \mathrm{C}$ for 40 seconds, and finally at $73^{\circ} \mathrm{C}$ for six minutes. PCR of $I L-4$ (VNTR) was directly visualized on $2 \%$ agarose gel stained with ethidium bromide, and finally, alleles were identified based on the sizes of amplified fragments. The $R p 2$ and $R p 1$ alleles were 253- and 183-bp fragments, respectively (Figure 1). 
The $I L-10$ promoter polymorphism (PCR-restriction fragment length polymorphism) as described by Turner et al., (15) was used to detect the -592 SNP by introducing two alleles, A and C (A-C). A 100-ng of genomic DNA was amplified in a $25 \mathrm{~mL}$ final volume containing $1.5 \mathrm{mM}$ MgCL2, 10X KCL buffer, 25 pmol of each primer, $0.2 \mathrm{mM}$ of each dNTP, and 1 unit of Taq polymerase was used. The cycling conditions were as follows: $95^{\circ} \mathrm{C}$ for five minutes followed by 35 cycles at $94^{\circ} \mathrm{C}$ for 40 seconds, $61^{\circ} \mathrm{C}$ for one minute, $72^{\circ} \mathrm{C}$ for 40 seconds, and finally, $72^{\circ} \mathrm{C}$ for 10 minutes. The PCR product was a 412-bp fragment and the restriction fragment length polymorphism assay was performed in a $15-\mathrm{mL}$ reaction mixture containing PCR product $(10 \mathrm{~mL})$, buffer $(1.8 \mathrm{~mL})$, enzyme (Rsa), and distilled water $(3 \mathrm{~mL})$. The reaction mixture was incubated at $37^{\circ} \mathrm{C}$ for 16 hours. However, at position -592, 412-bp fragments were amplified and digested $\mathrm{A}$ allele with $\mathrm{RSaI}$ site demonstrated a two fragments, 236- and 176-bp, whereas the $-592 \mathrm{C}$ allele without RSa site produced no splitting (Figure 2).

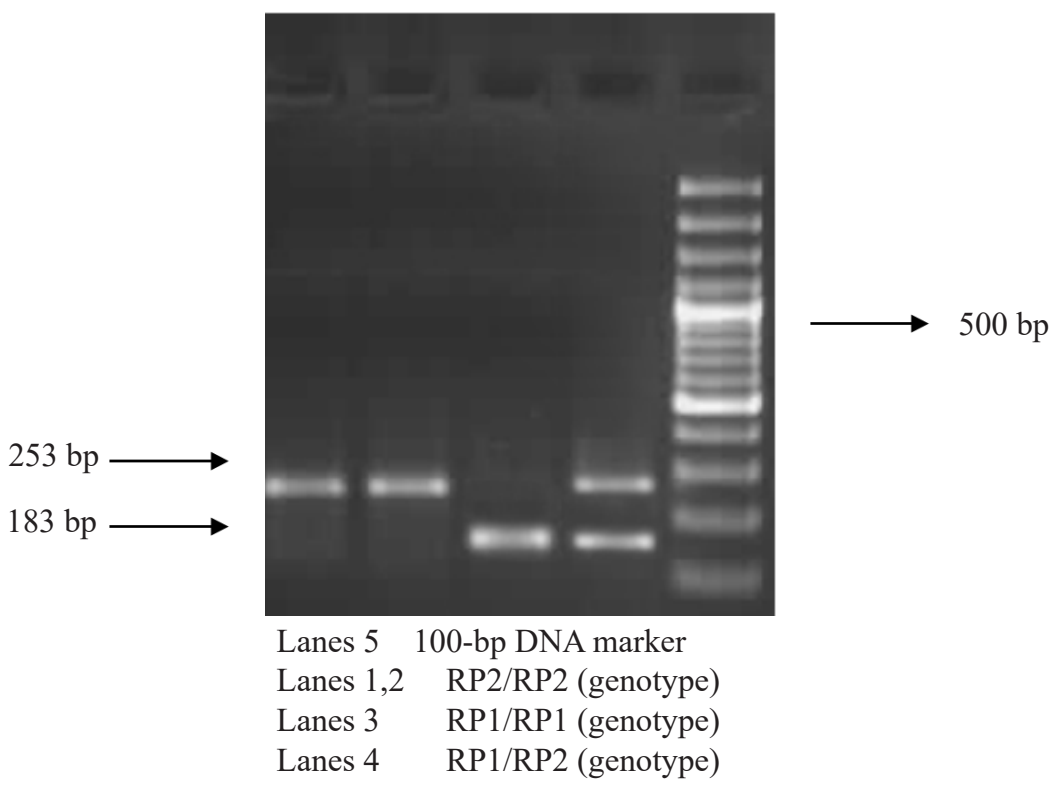

Figure 1. PCR-VNTR genotype analysis of $I L-4$ gene in the case group

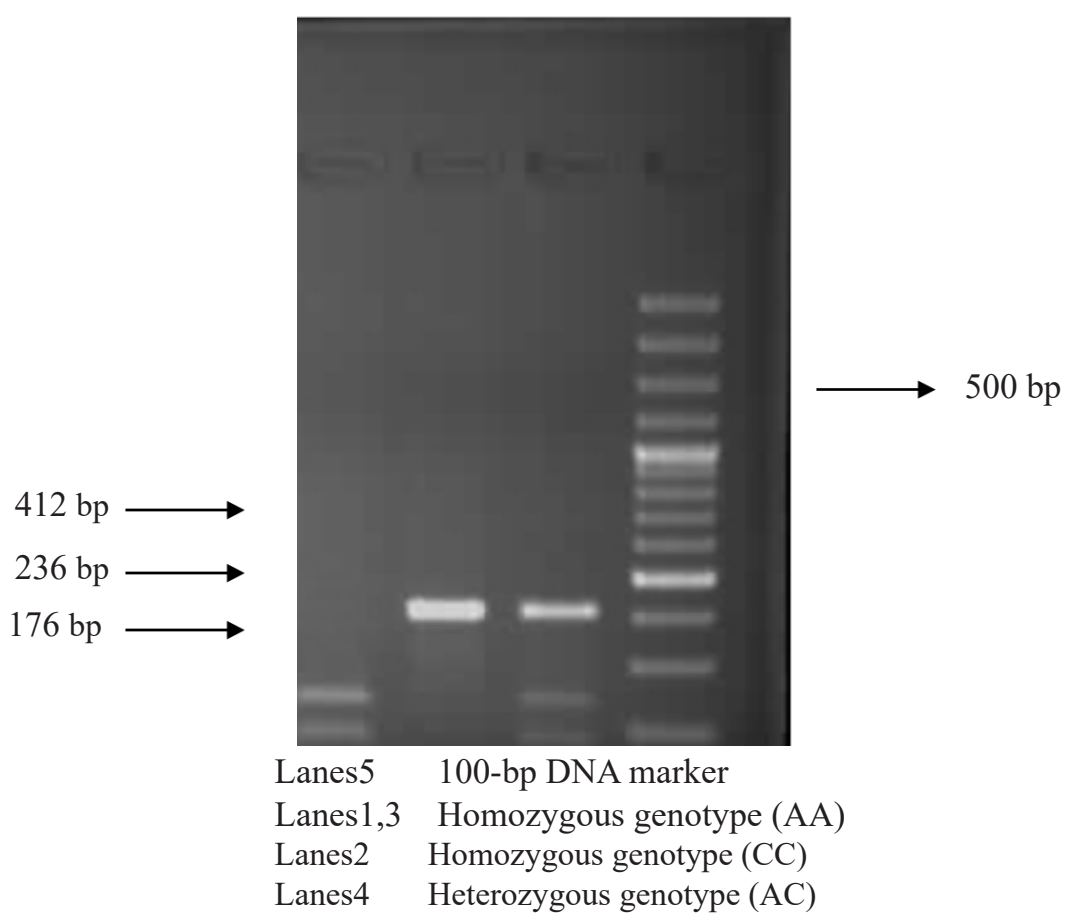

Figure 2. PCR-VNTR (Rsa1) genotype analysis of $I L-10$ gene in the case groups 


\section{Statistical Analysis}

In the current study, Hardy-Weinberg equilibrium for alleles at individual loci was assessed by $\chi 2$ test. Comparison of $I L-10$ (-592) and $I L-4$ genotype frequencies between the case and control groups were performed by $\chi 2$ test. Crude odds ratios (ORs) with 95\% confidence interval (CI) were calculated by logistic regression analysis. Statistical analysis was conducted with SPSS (SPSS16.0, SPSS Co., Seoul, Korea) and the P-value $<0.05$ was considered statistically significant.

\section{Results}

A total of 603 people including 198 patients with gastritis, 84 with peptic ulcer, and 321 healthy controls were studied. The mean age of the patients with gastritis was 41 years, ranged 17-85; the patients with peptic ulcer had the mean age of 42 years, ranged 2372. Subjects in the control group had the mean age of 41 years, ranged 21-74. There were significant differences between the three groups in terms of family history of ulcer and smoking habits. Demographic characteristics are shown in Table 1.

The genotype frequency distribution for $I L-4$ RP1/ RP2 was 99.5\% among patients with chronic gastritis, $96.4 \%$ among patients with peptic ulcer, and $94.4 \%$ among the controls. Genotype AC in $I L-10$ was the most frequent in patients with gastritis $45.5 \%, 46.4 \%$ in peptic ulcer, and $51.4 \%$ in the control group.

No significant relationship was observed between genotype and allele frequencies in $I L-10$ and none in patients with gastritis and peptic ulcer in $I L-4$ either. Genotypes $I L-4$ and $I L-10$ are presented in tables 2 and 3.

Table 1. Demographic Characteristics of the Cases and Controls

\begin{tabular}{lccc}
\hline & Gastritis (N=198) & Peptic Ulcer (N=84) & Control (N=321) \\
\hline Age, yr & $41.2 \pm 16.1$ & $42.8 \pm 15.5$ & $41.8 \pm 15.9$ \\
Male & $103 \pm 52$ & $40 \pm 47.6$ & $162 \pm 50.4$ \\
\hline Female & $95 \pm 48$ & $44 \pm 52.4$ & $159 \pm 49.6$ \\
\hline Smokers & $67 \pm 33.8$ & $34 \pm 40.5$ & $51 \pm 15.9$ \\
\hline Nonsmokers & $131 \pm 66.2$ & $50 \pm 59.5$ & $270 \pm 84.1$ \\
\hline
\end{tabular}

Data are expressed as mean $\pm \mathrm{SD}$.

Table 2. OR and 95\% CI for $I L-4$ and $I L-10$ Genotypes in Gastritis Cases and Controls

\begin{tabular}{|c|c|c|c|c|c|}
\hline Polymorphism & Genotype & $\begin{array}{c}\text { Gastritis } \\
(\mathrm{N}=198)\end{array}$ & $\begin{array}{l}\text { Control } \\
(\mathrm{N}=321)\end{array}$ & OR & P value \\
\hline \multirow[t]{4}{*}{ IL-4 } & RP1-RP1 & $9(4.5)$ & $18(5.6)$ & 1.0 & - \\
\hline & RP1-RP2 & $48(24.2)$ & $63(19.6)$ & $1.52(0.58-4.05)$ & 0.47 \\
\hline & RP2-RP2 & $141(71.3)$ & $240(74.8)$ & $1.17(0.48-2.91)$ & 0.86 \\
\hline & RP1-RP2+RP2-RP2 & $189(95.5)$ & $303(94.4)$ & $1.25(0.52-3.07)$ & 0.74 \\
\hline \multirow[t]{4}{*}{ IL-10 } & AA & $104(52.5)$ & $153(47.7)$ & 1.0 & - \\
\hline & $\mathrm{AC}$ & $90(45.5)$ & $165(51.4)$ & $0.80(0.55-1.17)$ & 0.26 \\
\hline & $\mathrm{CC}$ & $4(2.0)$ & $3(0.9)$ & $1.96(0.36-11.30)$ & 0.30 \\
\hline & $\mathrm{AC}+\mathrm{CC}$ & $94(47.5)$ & $168(52.3)$ & $0.82(0.57-1.19)$ & 0.32 \\
\hline
\end{tabular}

OR, odds ratio 
233. The Association of Gastritis and ...

Table 3. OR and 95\%CI for $I L-4$ and $I L-10$ Genotypes in Peptic Ulcer Cases and Controls

\begin{tabular}{cccccc}
\hline Polymorphism & Genotype & $\begin{array}{c}\text { Peptic } \\
\text { Ulcer(N=84) }\end{array}$ & $\begin{array}{c}\text { Control } \\
(\mathbf{N}=321)\end{array}$ & OR & P-value \\
\hline IL-4 & RP1-RP1 & $3(3.6)$ & $18(5.6)$ & 1.0 & - \\
& RP1-RP2 & $18(21.4)$ & $63(19.6)$ & $1.74(0.41-8.26)$ & 0.31 \\
\hline RP2-RP2 & $63(75)$ & $240(74.8)$ & $1.58(0.42-6.95)$ & 0.34 \\
RP1-RP2+RP2-RP2 & $81(96.4)$ & $303(94.4)$ & $1.60(0.43-7.03)$ & 0.33 \\
& AA & $42(50)$ & $153(47.7)$ & 1.0 & - \\
AC & $39(46.4)$ & $165(51.4)$ & $0.86(0.51-1.44)$ & 0.63 \\
& CC & $3(3.6)$ & $3(0.9)$ & $3.64(0.56-23.68)$ & 0.12 \\
& AC+CC & $42(50)$ & $168(52.3)$ & $0.91(0.55-1.51)$ & 0.79 \\
\hline
\end{tabular}

OR, odds ratio

\section{Discussion}

The responses of the host $/$ s immune system including cytokine activity play an important role in causing gastritis due to infections such as $H$. pylori, and ultimately in the progress of the disease and more advanced clinical complications such as gastrointestinal ulcers, and specifically gastric and duodenal ulcers, and also stomach and gastric cancer. Many genetic studies proposed a relationship between cytokines and diseases associated with the immune system. Yet, despite studies on cytokines and their genetic role and different genotypes and polymorphisms, the relationship between different polymorphisms of the host>s cytokines and severity or nature of the disease remains unclear (16). The current study aimed at ext amining $I L-4$ and $I L-10$ because they act in two different systems of the cytokine immune response. The current study specifically focused on the significance of two polymorphisms of two anti-inflammatory cytokines, $I L-4$ and $I L-10$, in a population of normal controls and H. pylori-related gastric disease groups, but since no clear data were observed on the role of $I L-4$ in bacterial infections, its role in the systemic infections requires further investigation (17).

It is found that $I L-4$ has an inhibitory role in the expression, production, and release of inflammatory cytokines and can suppress activity, production, or release of cytokines derived from monocytes such as tumor necrosis factor (TNF), IL-1, IL-6, IL-8, and macrophage inflammatory protein (MIP)-1 $\alpha$. Other activities attributed to $I L-4$ include its effect on different body cells including increased proliferation of vascular endothelium and skin fibroblasts, and decreased proliferation of spherocytes and vascular smooth muscle cells (17). IL-4 acts through inhibition of $I F N-\gamma$, which is in fact inhibition of macrophages, and inhibits cell-dependent immune reactions (18). Since $I L-4$ has a wide variety of activities, perhaps this is the reason why no specific role is identified for this cytokine. Therefore, the diversity in $I L-4$ activities may also be a reason for contradictory results in different studies. Besides, $I L-10$ is an anti-inflammatory cytokine responsible for the development and differentiation of B-cells, inhibition of immunological responses, and prevention of B-cells activities.

$I L-10$ is also the main cytokine against anti-inflammatory cytokines TNF- $\alpha(9,19)$.

In the current study, no significant relationship was observed between being a carrier of any alleles or combination of alleles and the development of inflammation, gastritis, and thus gastric cancer. There may be different conditions underlying the genetics of $\mathrm{H}$. 
Pylori-related gastritis and gastric cancer. Although no specifically similar study is conducted, these polymorphisms are studied separately or in other diseases or cancers.

In agreement with the current study results, Rad et al., reported no significant relationship between being carrier of low-frequency or risk alleles in $I L-10-592$ and atrophic gastritis and intestinal metaplasia (20). Moreover, another study in China observed no association between intestinal metaplasia and $I L-10$ polymorphisms, which also confirmed the current study results on $I L-10-592$ polymorphism (21). Hunt PJ and Yam-Yao found a significant relationship between $I L$ 10-592 and VNTR intron 3 of $I L-4$ and other diseases such as rheumatism, arthritis, asthma, rhinitis, Atopic dermatitis, gravies disease, multiple sclerosis, and bladder cancer, which may be due to the role of immune system and immune responses in such diseases $(22,23)$.

According to the current study results, it might be concluded that regardless of other confounding and environmental factors and regarding only gender and age, these polymorphisms in the two sites in these two cytokines do not pose any increased or decreased risk for gastritis and peptic ulcer following $H$. pylori infection. As discussed earlier, the role of these cytokines in the inflammatory diseases is not yet fully understood, and thus these results cannot be considered definitive. Another reason for uncertainty is the role of haplotypes in these cytokines. Studies revealed that different haplotypes affect secretion of cytokines, which was not investigated in the current study, and requires further studies.

\section{Acknowledge}

I would like to express my deepest appreciation to staffs of Molecular Medicine Research Center of HormozganUniversity of Medical Sciences who provided me the possibility to complete this article.

\section{Conflict of interest}

The authors declared no conflict of interests.

\section{References}

1. Vannarath S, Vilaichone RK, Rasachak B, Mairiang P, Yamaoka Y, Shiota S, et al. Virulence genes of helicobacter pylori in gastritis, peptic ulcer and gastric cancer in Laos. Asian Pac J Cancer Prev. 2014;15(20):9027-31. https://doi.org/10.7314/APJCP.2014.15.20.9027 PMID:25374247

2. QadriQ, Rasool R, Afroze D, Naqash S, Gulzar G, Yousuf A, et al. Study of TLR4 and IL-8 Gene Polymorphisms in H. pylori-Induced Inflammation in Gastric Cancer in an Ethnic Kashmiri Population. Immunol Invest. 2014;43(4):32436. https://doi.org/10.3109/08820139.2013.854378 PMID:24295404

3. El-Omar EM, Carrington M, Chow W-H, McColl KE, Bream JH, Young HA, et al. Interleukin-1 polymorphisms associated with increased risk of gastric cancer. Nature. 2000;404(6776):398-402. https://doi. org/10.1038/35006081 PMID: 10746728

4. Kim J, Cho YA, Choi IJ, Lee Y-S, Kim S-Y, Shin A, et al. Effects of interleukin-10 polymorphisms, Helicobacter pylori infection, and smoking on the risk of noncardia gastric cancer. PloS one. 2012;7:e29643. https://doi.org/10.1371/ journal.pone. 0029643 PMID:22235320 PMCID:PMC3250465

5. Mocellin S, Marincola FM, Young HA. Interleukin-10 and the immune response against cancer: a counterpoint. J Leukoc Biol. 2005;78(5):1043-51. https://doi.org/10.1189/ jlb.0705358 PMID: $\underline{16204623}$

6. Xue H, Lin B, An J, Zhu Y, Huang G. Interleukin-10-819 promoter polymorphism in association with gastric cancer risk. BMC Cancer. 2012;12(1):102. https://doi. org/10.1186/1471-2407-12-102 PMID:22436502 PMCID:PMC3384469

7. Burada F, Angelescu C, Ioana M, Mitrut P, Moraru E, Riza A, et al. IL-10-1082 A/G POLYMORPHISM AND RISK OF THE GASTRIC CANCER. Annals of RSCB. 2010;15(1):937. http://www.annalsofrscb.ro/archive/15\%20 
235. The Association of Gastritis and ...

1/1583-6258.XV-1-2010.93-97.pdf

8. El-Omar EM, Rabkin CS, Gammon MD, Vaughan TL, Risch HA, Schoenberg JB, et al. Increased risk of noncardia gastric cancer associated with proinflammatory cytokine gene polymorphisms. Gastroenterology. 2003;124(5):1193-201. https://doi.org/10.1016/ S0016-5085(03)00157-4 PMID: 12730860

9. Sosroseno W, Herminajeng E, Goeno S. The interleukin network in the immunopathogenesis of oral diseases. Asian Pac J Allergy Immunol. 1994;12(2):161-8. PMID:7612111

10. Nakashima H, Miyake K, Inoue Y, Shimizu S, Akahoshi M, Tanaka Y, et al. Association between IL-4 genotype and IL-4 production in the Japanese population. Genes Immun. 2002;3(2):107-9. https://doi.org/10.1038/ sj.gene.6363830 PMID:11960309

11. Kesarwani P, Ahirwar D, Singh R, Manchanda PK, Mittal RD. Do IL-4 intron 3 VNTR and IL-6 (-174) G/C variants reflect ethnic variation? A comparative study between the global and North Indian populations. Asian Pac J Cancer Prev. 2008;9(1):76-80. PMID: 18439079

12. Stolte M, Meining A. The updated Sydney system: classification and grading of gastritis as the basis of diagnosis and treatment. Can J Gastroenterol. 2001;15(9):591-8. https://doi. org/10.1155/2001/367832 PMID:11573102

13. Wu M, Huang C, Tsai JJ, Chen H, Tsai F. Polymorphisms of the interleukin-4 gene in Chinese patients with systemic lupus erythematosus in Taiwan. Lupus. 2003;12(1):21-5. https://doi. org/10.1191/0961203303lu249oa PMID: 12587822

14. Turner D, Williams D, Sankaran D, Lazarus M, Sinnott P, Hutchinson I. An investigation of polymorphism in the interleukin-10 gene promoter. Eur JImmunogenet. 1997;24(1):1-8. https://doi.org/10.1111/j.1365-2370.1997.tb00001.x

15. Murphy G, Thornton J, McManus R, Swan $\mathrm{N}$, Ryan B, O'Morain C, et al. Association of gastric disease with polymorphisms in the inflammatory related genes IL-1B, IL-1RN, IL-
10, TNF and TLR4. Eur J Gastroenterol Hepatol. 2009;21(6):630-5. https://doi.org/10.1097/ MEG.0b013e3283140eea PMID:19295440 PMCID:PMC2802816

16. Brown MA, Hural J. Functions of IL-4 and control of its expression. Crit Rev Immunol. 1997;17(1):31-2. PMID:

17. Shekari M, Kordi-Tamandani DM, MalekZadeh K, Sobti RC, Karimi S, Suri V. Effect of anti-inflammatory (IL-4, IL-10) cytokine genes in relation to risk of cervical carcinoma. Am J Clin Oncol. 2012;35(6):514-9. PMID:22157213

18. Gibson AW, Edberg JC, Wu J, Westendorp RG, Huizinga TW, Kimberly RP. Novel single nucleotide polymorphisms in the distal IL-10 promoter affect IL-10 production and enhance the risk of systemic lupus erythematosus. J Immunol. 2001;166(6):3915-22. https://doi.org/10.4049/ jimmunol.166.6.3915 PMID:112386636

19. Rad R, Dossumbekova A, Neu B, Lang R, Bauer S, Saur D, et al. Cytokine gene polymorphisms influence mucosal cytokine expression, gastric inflammation, and host specific colonisation during Helicobacter pylori infection. Gut. 2004;53(8):1082-9. https://doi. org/10.1136/gut.2003.029736 PMID:15247172 PMCID:PMC1774164

20. Leung WK, Chan MC, To K-F, Man EP, Ng EK, Chu ES, et al. H. pylori genotypes and cytokine gene polymorphisms influence the development of gastric intestinal metaplasia in a Chinese population. J Gastroenterol Hepatol. 2006;101(4):714-20. https://doi.org/10.1111/ j.1572-0241.2006.00560.x PMID: 16635219

21. Seno H, Satoh K, Tsuji S, Shiratsuchi T, Harada Y, Hamajima N, et al. Novel interleukin-4 and interleukin-1 receptor antagonist gene variations associated with non-cardia gastric cancer in Japan: comprehensive analysis of 207 polymorphisms of 11 cytokine genes. J Gastroenterol Hepatol. 2007;22(5):729-37. https://doi.org/10.1111/j.1440-1746.2007.04934.x PMID:17444864

22. Hunt P, Marshall S, Weetman A, Bell J, Wass 
J, Welsh K. Cytokine gene polymorphisms in autoimmune thyroid disease. J Clin Endocrinol Metab. 2000;85(5):1984-8. https://doi. org/10.1210/jcem.85.5.6588 PMID: 10843185
Ward H, Ferguson AC, Manfreda J, et al. Polymorphisms of the IL-4, TNF- $\alpha$, and Fc $\alpha$ RI $\beta$ genes and the risk of allergic disorders in At-risk infants. Am J Respir Crit Care Med. 2000;161(5):1655-9. https://doi.org/10.1164/ajrc$\underline{\mathrm{cm} .161 .5 .9906086}$ PMID:10806171

\section{How to Cite This Article}

Rezaeishahmirzadi M, Motamedi Rad N, Kalantar M, Ayatollahi H, shakeri S, Sheikhi M, Shekari M. The Association of Gastritis and Peptic Ulcer With Polymorphisms in the Inflammatory-related Genes IL-4 and IL-10 in Iranian Population. Iranian Journal of Pathology, 2018; 13(2): 229-236. 